\title{
Common ECG Lead Placement Errors. Part II: Precordial Misplacements
}

\author{
Allison V. Rosen, ${ }^{1}$ Sahil Koppikar, ${ }^{2}$ Catherine Shaw, ${ }^{3}$ Adrian Baranchuk. ${ }^{3}$
}

\begin{abstract}
Background: Electrocardiography is a very useful diagnostic tool. However, errors in placement of ECG leads can create artifacts, mimic pathologies, and hinder proper ECG interpretation. This is the second of a two-part series discussing how to recognize and avoid these errors. Methods: 12-lead ECGs were recorded in a single male healthy subject in his mid 20s. Various precordial lead misplacements were compared to ECG recordings from correct lead placement. Results: Precordial misplacements caused classical changes in ECG patterns. Techniques of differentiating these ECG patterns from true pathological findings were described. Conclusion: As in Part I of this series, recognition and interpretation of common ECG placement errors is critical in providing optimal patient care.
\end{abstract}

Keywords: Cardiology, Electrocardiography, Medical Errors, Precordial Lead Placement, Medical Education (Source: MeSH-NLM).

\section{Introduction}

As discussed in Part I of this series, electrocardiography (ECC) has been established as a useful diagnostic tool. ${ }^{1-3}$ Accuracy in ECG recording, whether from trained experts or other medical professionals, is essential in order to reliably interpret medical information. ${ }^{4}$ If ECGs are recorded or interpreted by inexperienced individuals, results may be incorrectly interpreted, and patients may be treated according to false information. ${ }^{5-9}$ There are characteristic ECG placement errors that can be recognized, and the REVERSE mnemonic can facilitate recognition of placement errors based on abnormal ECG findings. ${ }^{10}$

About the Author: Allison Rosen is currently in her third year of medical school at Queen's University, Kingston, Canada. She is the Editor-in-Chief of the Queen's Medical Review and an active member of the Class Council.
Electrode misplacements have been shown to occur in as many as $4 \%$ of recordings in intensive care units. ${ }^{2,11}$ When considering both limb lead reversals and precordial reversals, it is perhaps easy to imagine how limb leads might be mistakenly applied; all are long leads, and left and right sides might be confused on swift application of leads. Contrastingly, precordial leads are bundled together as a group. This explains the low frequency of limb and precordial lead reversals. ${ }^{12}$ Precordial errors isolated to the precordial leads are expanded on more in this paper, where we discuss complete reversals of leads V1-V6. Additionally, inaccurate placement of precordial leads poses a significant problem. Leads $V_{1}$ and $V_{2}$ can be placed either too high or too low, causing characteristic findings in each case. ${ }^{13}$ This type of error involving $V_{1}$ and $V_{2}$ occurs in up to $50 \%$ of ECG recordings. ${ }^{14}$

The purpose of this study is to review some of the most common recording errors. For the purpose of clarity, this work has been divided into two parts. Part I discussed limb lead reversals. ${ }^{2}$ Part II will deal with precordial placement errors.

\begin{abstract}
Methods
The same subject was analyzed as in Part I of this series, by the same technician and with the same ECG machine (General Electric, Mac 5500, United States) set up at $150 \mathrm{~Hz}, 25.0 \mathrm{~mm} / \mathrm{s}$, and $10.0 \mathrm{~mm} / \mathrm{V}$ (Figure 1). ${ }^{2} \mathrm{~A}$ series of precordial lead misplacements were conducted in order to recreate these classic patterns.
\end{abstract}

\section{Results}

\section{$V_{1}-V_{2}$ in Third Intercostal Space}

RSuperior placement of the $V_{1}$ and $V_{2}$ electrodes is a common error. ${ }^{15}$ The high position of these electrodes causes the $R$ wave amplitude to decrease by approximately $0.1 \mathrm{mV}$ in leads $\mathrm{V}_{1}-\mathrm{V}_{2}$ along with poor $\mathrm{R}$ wave progression across the precordial leads (Figure 2). ${ }^{16-19}$ Furthermore, the key to detecting a high $\mathrm{V}_{1}-\mathrm{V}_{2}$ placement is the absence of a positive $\mathrm{P}$ wave in $\mathrm{V}_{2}$, accompanied by a biphasic $P$ wave in $V_{1}$ with a predominantly negative component. However, the negative $P$ wave in $V_{1}$ is noted to be more important for discrimination purposes than V2 findings. 5,20

These findings can mimic an anterior or anteroseptal myocardial infarction, however, a negative $\mathrm{P}$ wave in $\mathrm{V}_{2}$ in conjunction with a biphasic $P$ wave in $V_{1}$ is not common in acute coronary syndromes. Furthermore, misplacement of $\mathrm{V}_{1}-\mathrm{V}_{2}$ electrodes can be confirmed by recording normal $\mathrm{R}$ wave progression from lower locations on the thorax. If an anterior infarct was the cause of the poor $\mathrm{R}$ wave progression, it would persist in the lower leads. ${ }^{17}$ The superior placement of $\mathrm{V}_{1}-\mathrm{V}_{2}$ electrodes can also potentially mimic Brugada syndrome. ${ }^{13}$ Brugada syndrome is a potentially lethal cardiac channelopathy that presents with distinct patterns in the right precordial leads $\mathrm{V}_{1}, \mathrm{~V}_{2}$, and $\mathrm{V}_{3}$. $^{2,22}$ The type 1 pattern has high sloping, coved type ST segments

${ }^{1}$ Queen's University School of Medicine, Kingston, Ontario, Canada.

2Department of Internal Medicine, Kingston General Hospital, Queen's University, Kingston, Ontario, Canada.

${ }^{3}$ Heart Rhythm Service, Kingston General Hospital, Queen's University, Kingston, Ontario, Canada.

\section{Correspondence:}

Adrian Baranchuk, MD FACC FRCPC. Associate Professor of Medicine, Cardiac Electrophysiology and Pacing, Kingston General Hospital, Queen's University.

Address: Cardiac Electrophysiology and Pacing, Kingston General Hospital K7L 2V7, Queen's University, Kingston, Canada.

Email: barancha@kgh.kari.net 
Figure 1. 12 lead ECG depicting correct lead placement. (A) ECG recording. (B) Correct lead placements on chest and arms.

A

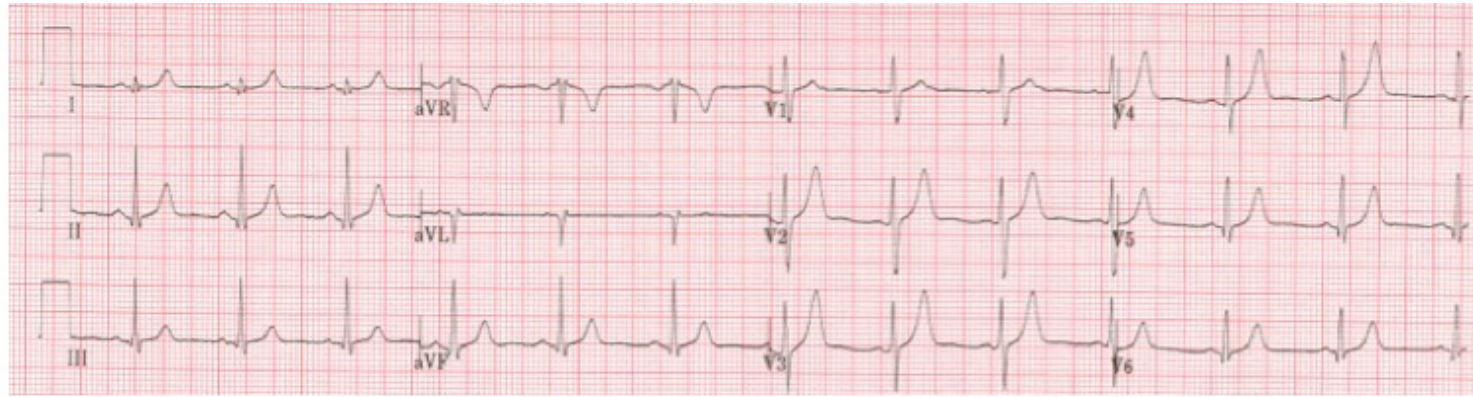

B

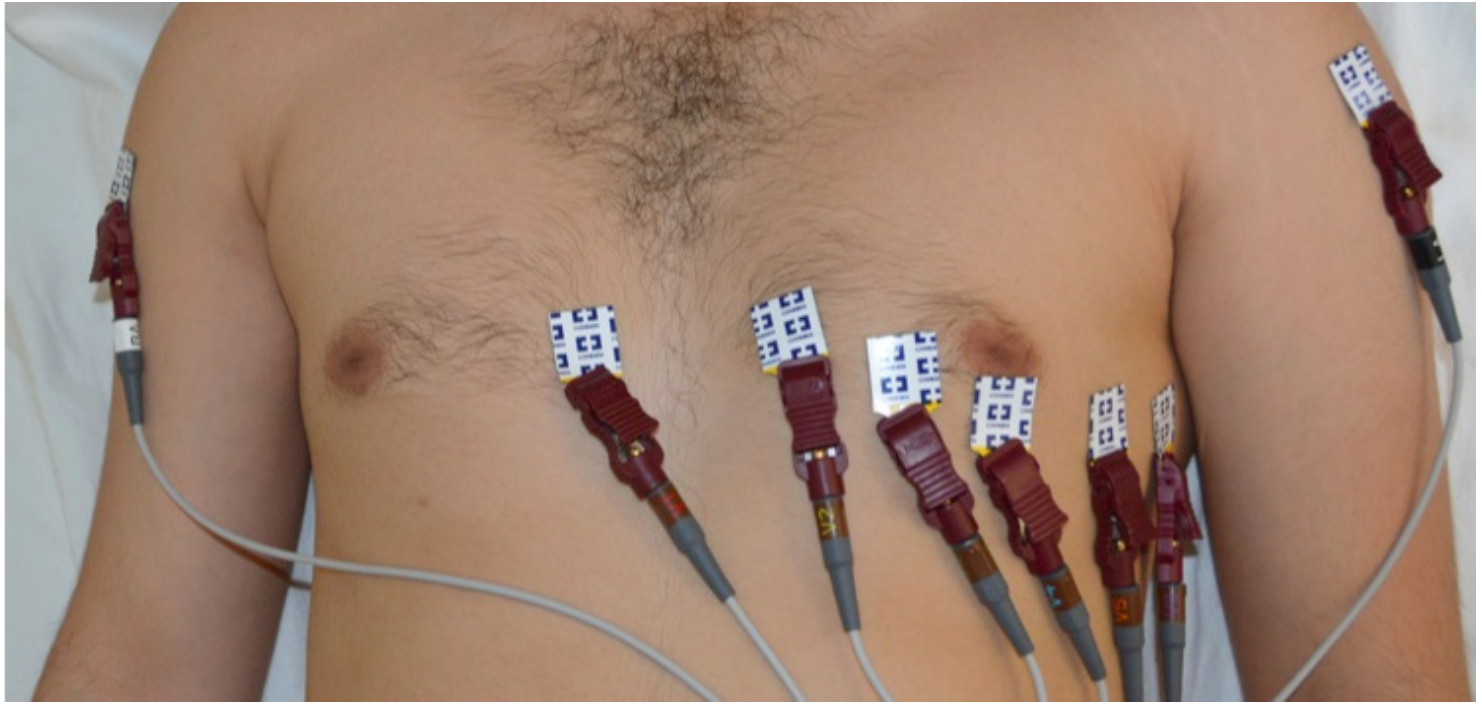

Figure 2. 12 lead ECG depicting $V_{1}$ and $V_{2}$ placed in the third intercostal space. (A) ECG recording. (B) Arrows point to reversal of leads on precordium.

A

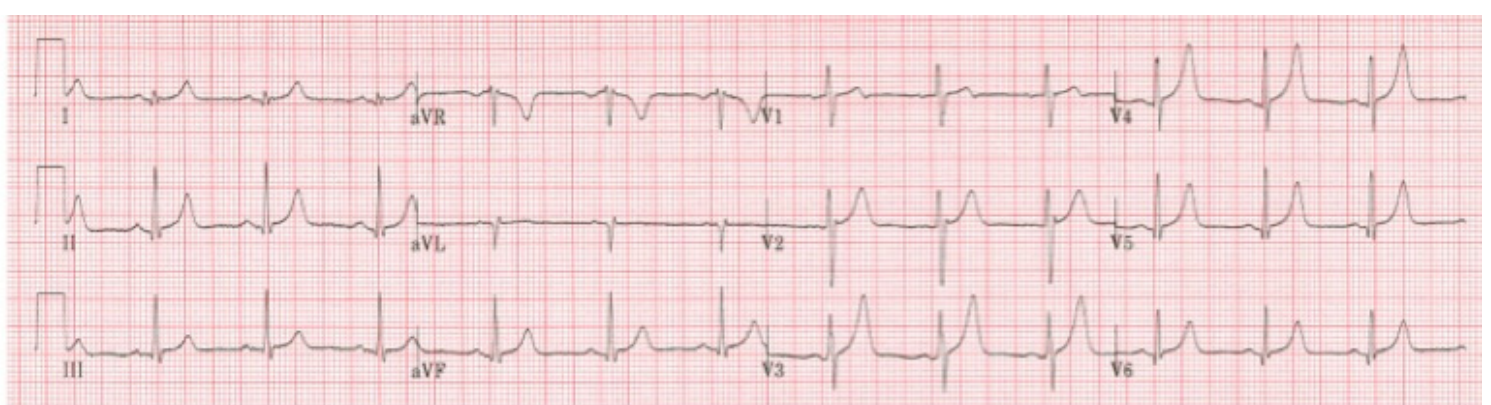

B

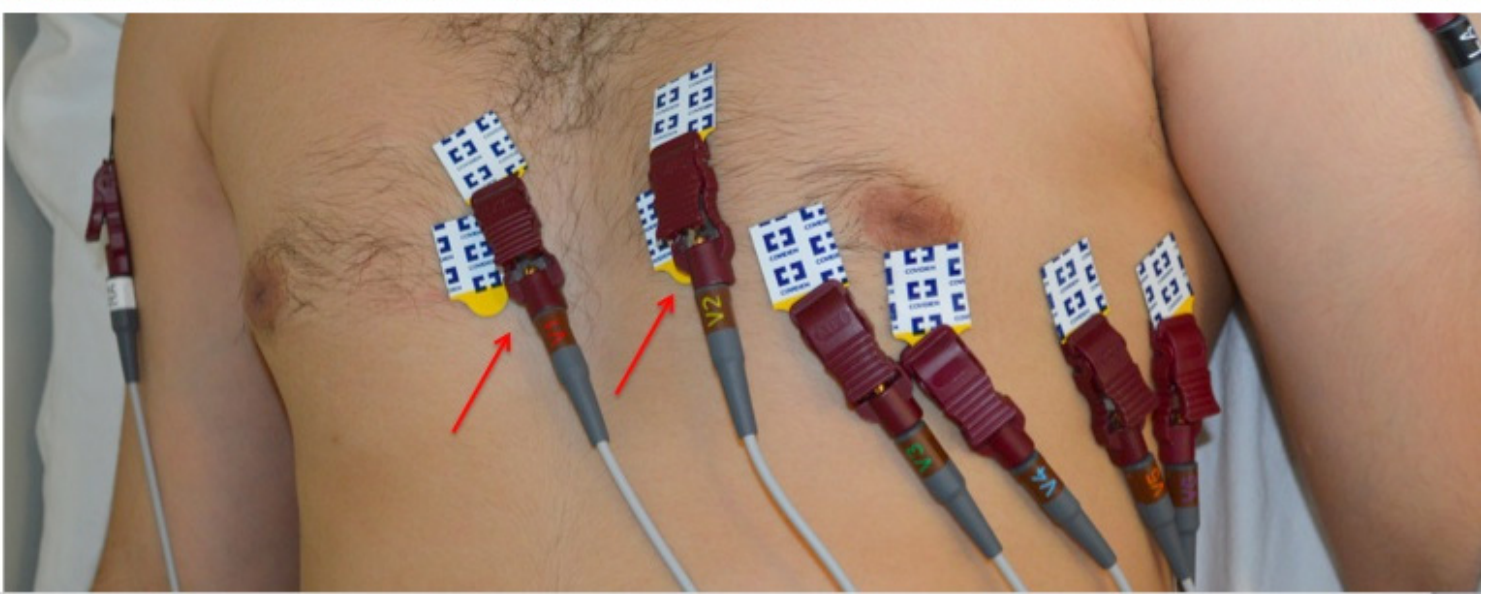


with negative T-waves. The type 2 pattern has high elevated, saddle back ST segments with variable or flat T-waves in $\mathrm{V}_{1}$ or V2. Brugada syndrome can be mimicked by a number of causes, including improper use of high and low-pass filters, and can be difficult to observe in patients with cardiac abnormalities such as arrhythmias, ${ }^{23-25} \mathrm{r}^{\prime}$ waves in leads $\mathrm{V}_{1}-\mathrm{V}_{2},{ }^{26}$ or pectus excavatum. ${ }^{27}$ As Brugada syndrome is potentially lethal, but also easily obscured by filters or other errors, it is important to carefully ensure none of these errors persist if the diagnosis is suspected. ${ }^{28}$ Brugada syndrome can be differentiated from electrode misplacement by noting an absence of the clinical criteria required for diagnosis along with a normalization of the ECG upon placing the electrodes on lower locations on the thorax. ${ }^{29,30}$

\section{$V_{1}-V_{2}$ in Fifth Intercostal Space}

Inferior placement of the $\mathrm{V}_{1}-\mathrm{V}_{2}$ electrodes does not produce a significantly altered ECG, and can go unrecognized in many cases (Figure 3). The major change noted is that the low position of these electrodes can cause the $R$ wave amplitude to increase by approximately $0.1 \mathrm{mV}$ in leads $\mathrm{V}_{1}-\mathrm{V}_{2}$ per inferior interspace. ${ }^{17}$

\section{V1-V6 Reversal}

Exchanging two or more precordial leads is another common error. ${ }^{31}$ The major finding in these errors is abnormal progression of the $\mathrm{R}$ wave in the affected leads (Figure 4). In a normal $E C G$, lead $V_{1}$ shows an rS-type complex, with a steady increase in the size of the $R$ wave and decrease in the $S$ wave amplitude as it moves towards V6. Leads $V_{5}$ and $V_{6}$ will predominantly show a GR-type complex. However, in the case of precordial lead reversals, one or more electrodes have a marked deviation from this progression, and this standout area is representative of the misplaced precordial lead or leads..$^{5,20}$ In this specific case, the ECG shows an unexpectedly tall $\mathrm{R}$ wave in $\mathrm{V}_{1}$ and a deep $S$ wave in V6. As these two leads do not follow the expected pattern, it should raise the suspicion for a $\mathrm{V}_{1}-\mathrm{V}_{6}$ lead reversal.

On a quick examination of the ECG, a V1-V6 reversal can be potentially misinterpreted as a right bundle branch block (RBBB). ${ }^{5}$ However, a RBBB presents with a RSR' pattern rather qR-type complex. Additionally, the lateral leads $\left(I, a V L, V_{5}-V_{6}\right)$ may present with a wide, slurred $S$ wave along with ST depression and $\mathrm{T}$ wave inversion in $\mathrm{V}_{1}-\mathrm{V}_{3}$, neither of which are observed in a V1-V6 reversal. A V1-V6 reversal can also be mistaken for right ventricular hypertrophy (RVH). ${ }^{5}$ While $\mathrm{RVH}$ has a dominant $\mathrm{R}$ wave in $V_{1}$ and a dominant $S$ wave in $V_{5}$ or $V_{6}$, there is also a right axis deviation, which is not observed in a $\mathrm{V}_{1}-\mathrm{V} 6$ lead reversal.

It is important to note that swapping of precordial leads with limb leads may occur, but is rarely noticed, since the physical bonds between the six precordial leads makes this misplacement difficult. ${ }^{31}$

\section{V1-V6 Complete Reversal}

A complete reversal of all the precordial electrodes results in the reversal of the $R$ wave progression. The $R$ wave will decrease its amplitude from $V_{1}$ to $V_{6}$ and the $S$ wave will increase its amplitude (Figure 5). This is similar to findings in dextrocardia or a posterolateral myocardial infarction. ${ }^{31}$ Dextrocardia would present with inversion of $P$ waves and QRS complexes in leads $\mathrm{I}$ and $\mathrm{aVL}$, along with poor $\mathrm{R}$ wave progression. Precordial lead reversal can be differentiated from dextrocardia since limb abnormalities would not be found in the case of a reversal. ${ }^{5,20,31} \mathrm{~A}$ posterolateral infarction would present with tall broad $R$ waves in $\mathrm{V}_{1}-\mathrm{V}_{3}$, upright $\mathrm{T}$ waves and horizontal ST depression. While tall $R$ waves and upright $T$ waves can be seen in the case of a V1-V6 complete reversal, the ST depressions are not present, and can help rule out a posterior infarct.

Figure 3. 12 lead ECG depicting $V_{1}$ and $V_{2}$ placed in the fifth intercostal space. (A) ECG recording. (B) Arrows point to reversal of leads on precordium.

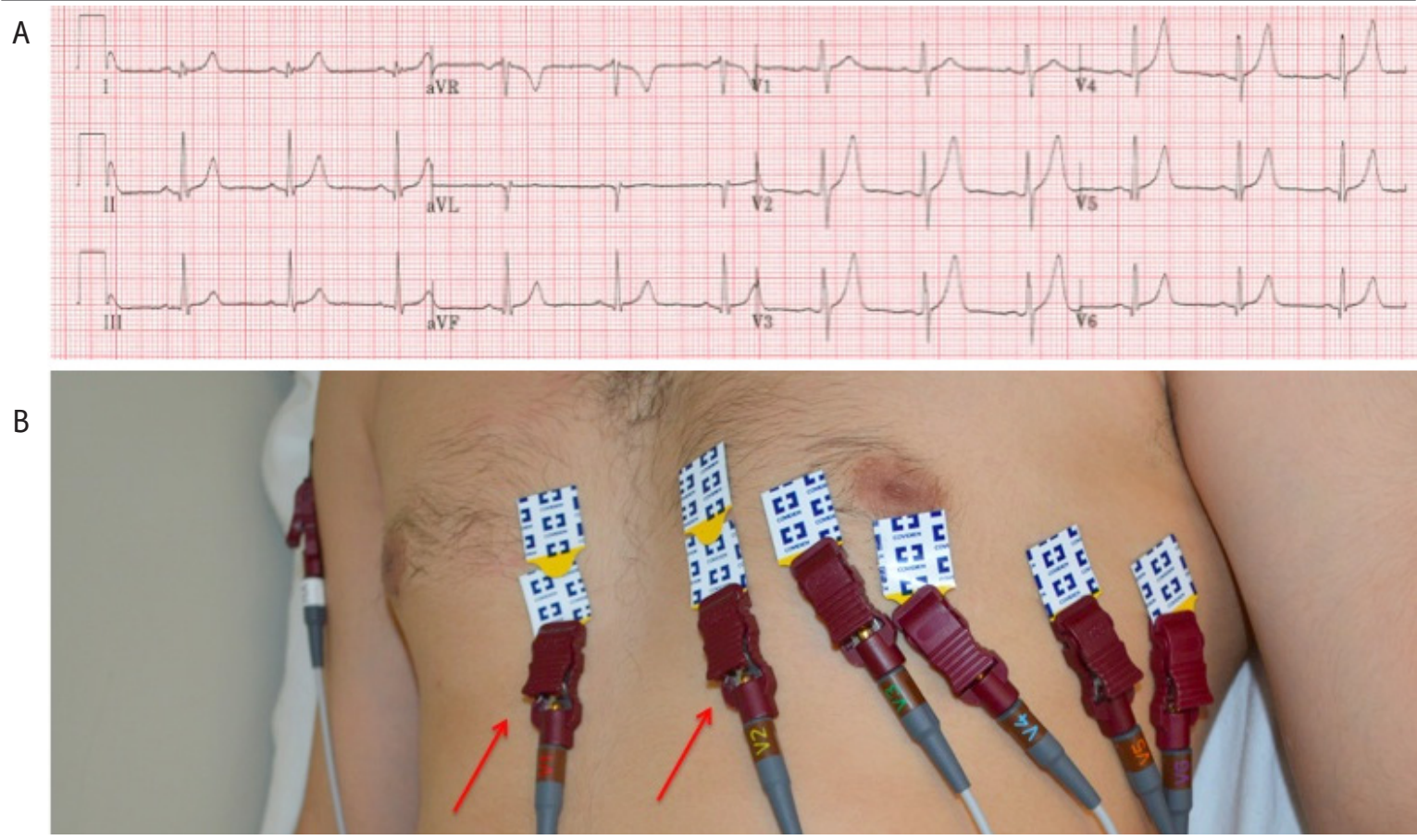


Figure 4. 12 lead ECG depicting reversal of $\mathrm{V}_{1}$ and V6. (A) ECG recording. (B) Arrows point to reversal of leads on precordium.

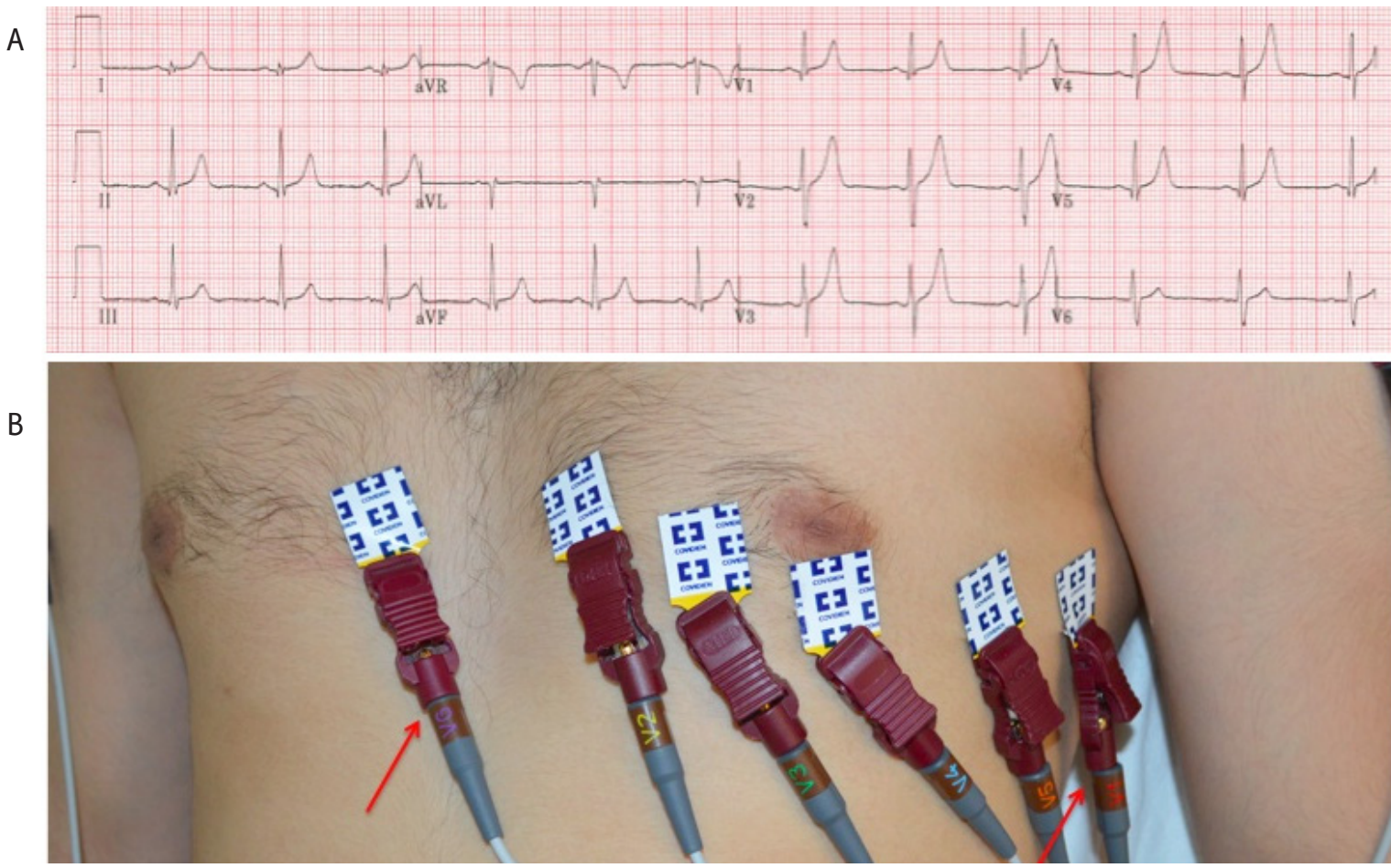

Figure 5. 12 lead ECG depicting complete reversal of leads V1-V6. (A) ECG recording. (B) Arrows point to reversal of leads on precordium.

A

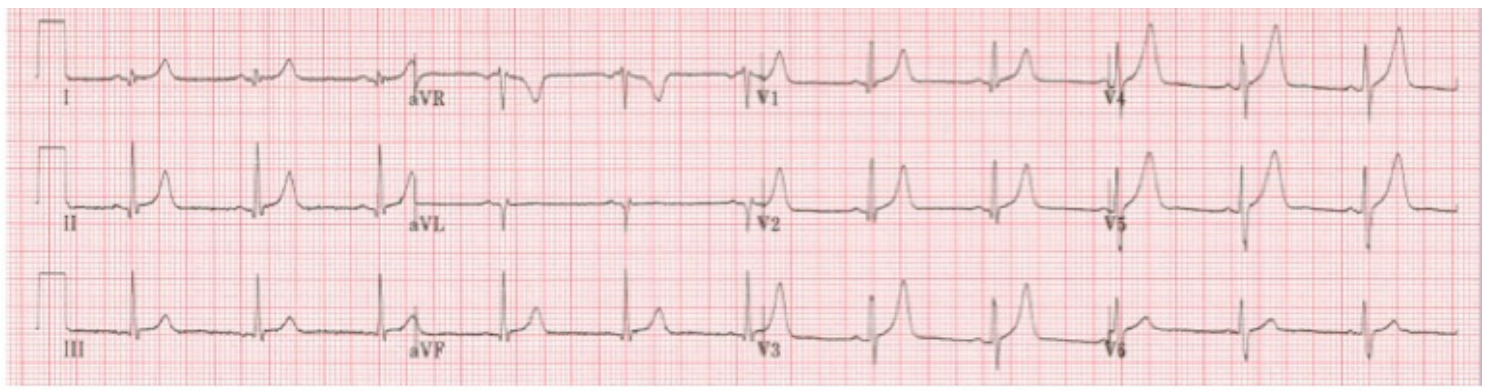

B

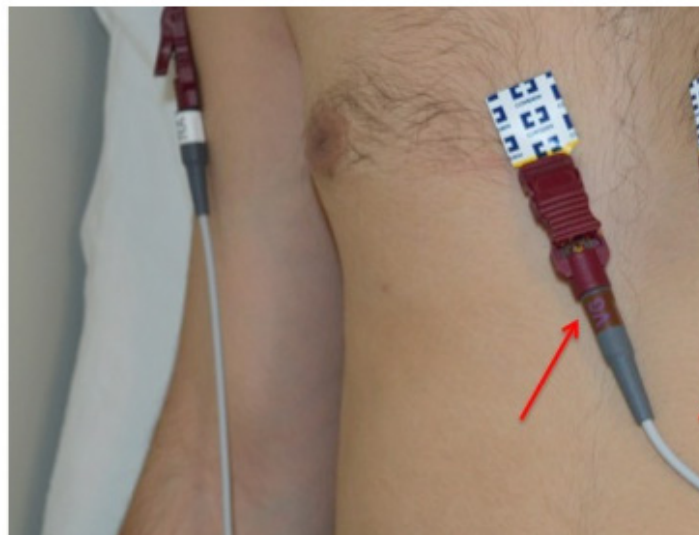

\section{Discussion}

Precordial electrode misplacements can lead to morphological changes on ECG that could potentially be interpreted as pathologic. Common misinterpretations of precordial lead misplacements can be myocardial infarction, genetic channelopathies such as Brugada syndrome, bundle branch blocks or pathologies such as dextrocardia. Electrode misplacements are common in outpatient clinics and intensive care units. ${ }^{5}$ Interes-

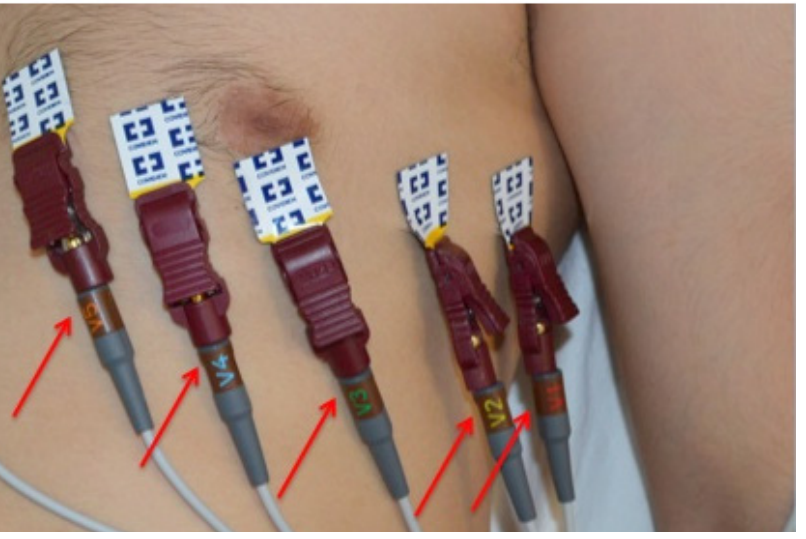

tingly, incorrect placement of specifically $V_{1}$ and $V_{2}$ has been estimated to occur in $50 \%$ of ECG recordings. ${ }^{15}$ The REVERSE mnemonic is a tool that outlines the most frequent abnormal findings on ECG. ${ }^{2,5}$ of note to our cases, reversal of precordial electrodes $V_{1}-V_{6}$ is identified in the mnemonic. Careful use of mnemonics such as REVERSE can eliminate errors in ECG recording and interpretation, leading to a reduction in false findings and an increase in diagnostic accuracy. 


\section{References}

1. Pérez-Riera A, Barbosa-Barros R, Baranchuk A. Current value of the electrocardiogram in the 21st century. Austin J Clin Cardiolog. 2014 Feb 24;1(2):1-3. 2. Rosen AV, Koppikar S, Shaw C, Baranchuk A. Common ECG lead placement errors. part I: Limb lead reversals. Int J Med Students. 2014 Jul-0ct;2(3):92-8. 3. Sclarovsky S, Garcia-Niebla J. Current role of electrocardiography in acute ischemic syndromes: Is it an outdated technique? Rev Esp Cardiol. 2009 Apr;62(4):456-459.

4. Kligfield P, Gettes LS, Bailey JJ, Childers R, Deal BJ, Hancock B, et al. Recommendations for the standardization and interpretation of the electrocardiogram: Part I: The electrocardiogram and its technology a scientific statement from the American Heart Association Electrocardiography and Arrhythmias Committee, Council on Clinical Cardiology; the American College of Cardiology Foundation; and the Heart Rhythm Society endorsed by the International Society for Computerized Electrocardiology. J Am Coll Cardiol. 2007 Mar;49(10):1109-1127.

5. Baranchuk A, Shaw C, Alanazi H, Campbell D, Bally K, Redfearn DP, et al. Electrocardiography pitfalls and artifacts: The 10 commandments. Crit Care Nurse. 2009 Feb;29(1):67-73.

6. Koppikar S, Shaw C, Baranchunk A. ECG quiz: A tale of an abnormal ECG. J Electrocardiol. 2014 Feb;47(1):123-125.

7. Bayes de Luna A, Goldwasser D, de Porta V, Fiol-Sala M, Carrillo A, Garcia-Niebla J, et al. Optimizing electrocardiographic interpretation in acute ST-elevation myocardial infarction may be very beneficial. Am Heart J. 2011 Jul;162(1):e1-2; author reply e5.

8. Batchvarov VN, Malik M, Camm AJ. Incorrect electrode cable connection during electrocardiographic recording. Europace. 2007 0ct 10;9(11):1081-1090. 9. Rudiger A, Hellermann JP, Mukherjee R, Follath F, Turina J. Electrocardiographic artifacts due to electrode misplacement and their frequency in different clinical settings. Am J Emerg Med. 2007 Feb;25(2):174-178.

10. Garcia-Niebla J, Llontop-Garcia P, Valle-Racero JI, Serra-Autonell C, Batchvarov VN, de Luna $A B$. Technical mistakes during the acquisition of the electrocardiogram. Ann Noninvasive Electrocardiol. 2009 0ct;14(4):389-403. 11. Sejersten M, Pahlm 0, Pettersson J, Zhou S, Maynard C, Feldman CL, et al. Comparison of EASI-derived 12-lead electrocardiograms versus paramedic-acquired 12-lead electrocardiograms using mason-likar limb lead configuration in patients with chest pain. J Electrocardiol. 2006 Jan;39(1):13-21.

12. Garcia-Niebla J, Garcia PL. An unusual case of electrode misplacement: Left arm and V(2) electrode reversal. J Electrocardiol. 2008 Sept-0ct;41(5):380-381. 13. Garcia-Niebla J, Baranchuk A, de Luna AB. True Brugada pattern or only high $V_{1}-V_{2}$ electrode placement? J Electrocardiol. 2014 May 5;47(5):756-758. 14. Harrigan RA, Chan TC, Brady WJ. Electrocardiographic electrode misplacement, misconnection, and artifact. J Emerg Med. 2012 Dec;43(6):1038-1044. 15. Wenger W, Kligfield P. Variability of precordial electrode placement during routine electrocardiography. J Electrocardiol. 1996 Jul;29(3):179-184.
16. Zema MJ, Luminais SK, Chiaramida S, Goldman M, Kligfield P. Electrocardiographic poor R wave progression III. the normal variant. J Electrocardiol. $1980 \mathrm{Apr} ; 13(2): 135-142$.

17. Garcia-Niebla J, Rodriguez-Morales $M$, Valle-Racero JI, de Luna AB. Negative $P$ wave in $V_{1}$ is the key to identifying high placement of $V_{1}-V_{2}$ electrodes in nonpathological subjects. Am J Med. 2012 Sept;125(9):e9-10; author reply e13.

18. Garcia-Niebla J. Comparison of p-wave patterns derived from correct and incorrect placement of $\mathrm{V}_{1}-\mathrm{V}_{2}$ electrodes. J Cardiovasc Nurs. 2009 MarApr;24(2):156-161.

19. Garcia-Niebla J. Morphologies suggestive of $V_{1}$ and $V_{2}$ lead misplacement. Rev Esp Cardiol. 2008 0ct;61(10):1109-1110.

20. Drew BJ. Pitfalls and artifacts in electrocardiography. Cardiol Clin. 2006 Aug;24(3):309-15, vii.

21. Bayes de Luna AB, Garcia-Niebla J, Baranchuk A. New electrocardiographic features in Brugada syndrome. Curr Cardiol Rev. 2014 Aug;10(3):175-180.

22. Bayes de Luna A, Brugada J, Baranchuk A, Borggrefe M, Breithardt $C$, Coldwasser $D$, et al. Current electrocardiographic criteria for diagnosis of Brugada pattern: A consensus report. J Electrocardiol. 2012 Sept;45(5):433-442.

23. Garcia-Niebla J, Serra-Autonell G, Bayes de Luna A. Brugada syndrome electrocardiographic pattern as a result of improper application of a high pass filter. Am J Cardiol. 2012 Jul 15;110(2):318-320.

24. Garcia-Niebla J, Serra-Autonell C. Effects of inadequate low-pass filter application. J Electrocardiol. 2009 Jul-Aug;42(4):303-304.

25. Diaz-Munoz J, Garcia-Niebla J. Brugada syndrome unmasked by oral flecainide in a patient with a history of supraventricular tachycardia. Semergen. 2014 Apr 2;37(1):61-69.

26. Serra G, Baranchuk A, Bayes-De-Luna A, Brugada J, Coldwasser D, Capluzini $L$, et al. New electrocardiographic criteria to differentiate the type-2 Brugada pattern from electrocardiogram of healthy athletes with $r$-wave in leads $V_{1} / V_{2}$. Europace. Epub 2014 Mar 6.

27. Awad SF, Barbosa-Barros R, Belem Lde S, Cavalcante CP, Riera AR, Garcia-Niebla J, et al. Brugada phenocopy in a patient with pectus excavatum: Systematic review of the ECG manifestations associated with pectus excavatum. Ann Noninvasive Electrocardiol. 2013 Sept;18(5):415-420.

28. Garcia-Niebla J, Serra-Autonell G, Fiol M, Bayes de Luna A. Brugada electrocardiographic pattern: Reality or fiction? J Electrocardiol. 2014 MayJun;47(3):362-363.

29. Anselm DD, Evans JM, Baranchuk A. Brugada phenocopy: A new electrocardiogram phenomenon. World J Cardiol. 2014 Mar 26;6(3):81-86.

30. Carcia-Niebla J, Diaz-Munoz J, Fiol M. Type 2 Brugada pattern is suggestive but not diagnostic of the syndrome. Am J Emerg Med. 2014 Jan;32(1):97-98. 31. Peberdy MA, Ornato JP. Recognition of electrocardiographic lead misplacements. Am J Emerg Med. 1993 Jul;11(4):403-405.

\section{Acknowledgments}

None.

Conflict of Interest Statement at Funding

The Authors have no funding, financial relationships or conflicts of interest to disclose.

Author Contributions

Conception and design the work/idea: AR AB. Collect data/obtaining results: AR SK CS. Analysis and interpretation of data: AR SK CS AB. Write the manuscript: AR SK. Critical revision of the manuscript: AR SK AB. Approval of the final version: $A B$. Contribution of patients or study material: SK CS AB. Administrative or technical advice: CS.

Cite as:

Rosen AV, Koppikar S, Shaw C, Baranchuk A. Common ECG Lead Placement Errors. Part II: Precordial Misplacements. Int J Med Students. 2014 Jul-0ct;2(3):99-103. 